Wójcik Piotr, Sobczyk Maciej, Słaboń Małgorzata, Chyćko Małgorzata, Więsyk Piotr, Rogowska Monika, Tomczyk Jan, Oleksa Paulina, Sobczyk Mateusz. Impact of different alcohol beverages on cardiovascular system. Journal of Education, Health and Sport. 2021;11(9):434-439. eISSN 2391-8306. DOI http://dx.doi.org/10.12775/JEHS.2021.11.09.056

https://apcz.umk.pl/JEHS/article/view/JEHS.2021.11.09.056

https://zenodo.org/record/5521152

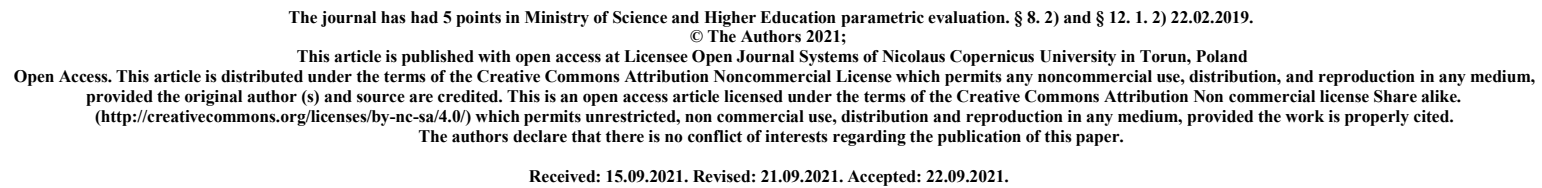

\title{
Impact of different alcohol beverages on cardiovascular system
}

Piotr Wójcik, Maciej Sobczyk ${ }^{1}$, Małgorzata Słabońn ${ }^{1}$, Małgorzata Chyćko ${ }^{1}$,

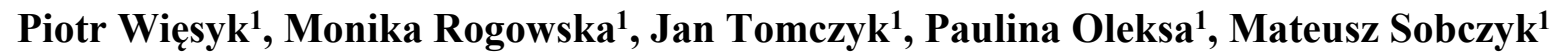

(1) Student Research Circle at the Department of Epidemiology and Clinical Research

Methodology, Medical University of Lublin, Poland

Corresponding author: Piotr Wójcik; piotrek1444@gmail.com

ORCID ID and e-mail:

Piotr Wójcik: https://orcid.org/0000-0002-9078-3701;

piotrek1444@gmail.com

Maciej Sobczyk: https://orcid.org/0000-0003-1857-2413;

maciejso@onet.pl

Małgorzata Słaboń: https://orcid.org/0000-0003-1627-8878;

malgorzata.slabon17@gmail.com

Małgorzata Chyćko: https://orcid.org/0000-0002-1515-6038;

malgorzatachycko@,gmail.com

Piotr Więsyk: https://orcid.org/0000-0001-6785-6741;

piotrwiesyk@gmail.com

Monika Rogowska: https://orcid.org/0000-0002-9078-3701;

m.rogowska98@gmail.com

Jan Tomczyk: https://orcid.org/0000-0003-1034-3819;

jantomczyk8@gmail.com

Paulina Oleksa: https://orcid.org/0000-0002-3474-6156;

gp.oleksa@,gmail.com

Mateusz Sobczyk: https://orcid.org/0000-0001-8690-2387; m.sobczyk1777@gmail.com

\section{Abstract}

Introduction: Alcohol is one of the most widely-used stimulants. It's easily accessible, most socially accepted and usually not associated with potential harm it can do. Except for its addictive effect, it has a strong influence on humane systems. 
In this analysis the influence of alcohol on the cardiovascular system will be examined. As it is not obvious whether alcohol usage should be only associated with harmful impact on cardiac activity, different types of alcoholic beverages should be examined.

In this work three different sub-groups will be analyzed. They were selected and divided by the beverage type and percentage as follows: beer, wine, high percentage liquors. As the majority of studies show, it's important to underline the significance of not only the alcohol percentage implied, but mostly of the alcohol type. In favor of alcoholic beverages are only studies analyzing beverages containing low levels of alcohol, but abundant in other organic substances like resveratrol (in wine). Other studies considering other beverages, nonetheless of alcohol levels, diminishing effect on the cardiovascular (and other) systems is observed.

Material and methods: An analysis of scientific papers from Pubmed Google Scholar was performed, wchoch most accurately described the issue of diffrent type of alcohol bevereage on human health. The following keywords were used in search: alcohol, cardiovascular, wine, beer, spirits.

Purpose of the work: Aim of the following analysis is to systematize the knowledge based on latest research and findings about the impact of different alcohol beverages on cardiovascular system.

Keywords: Cardiovascular; alcohol; wine; beer; spirits

\section{Introduction and purpose}

Cardiovascular deseases (CVD) are the main couse of death. In 2015 alone they coused $32 \%$ of deaths worldwide [1]. Since 1950's Framingham Heart Study there were studies on the modifiable risk factors. The risk of CVD can be modified by the seven risk factors; tabacco cessation, weight managment, physical activity, diet, blood cholesterol, blood glucose, blood pressure [2,3]. Alcohol consumption as a part of the diet has an impact on CVD prediction risk depending on the amount consumed, drinking frequency, pattern of consumtion and the type of beverage [4]. The diversity and difference between most common bevereges is significant. The purpose of the study is to reviev latest knowledge about the impact of dierent type of alcohol in moderate dose on human health.

\section{Description of the state of}

\subsection{Beer consumption effects.}

Beer is defined as an alcoholic beverage that is made by fermenting cereals and usually flavored with hops, containing approximately 5 percent of alcohol by volume (depending on the type, this can differ greatly). After water and tea it is the most consumed beverage in the world, making it important to know and understand its effects on the human health, especially on the cardiovascular system.

It is a well established fact that heavy alcohol drinking has a negative effect on multiple organ systems, as well as social problems, such as child abuse, suicide or an increased risk of traffic accidents [5]. In terms of cardiovascular diseases excessive alcohol consumption can contribute to developing systemic hypertension, atrial arrhythmias, hemorrhagic stroke and alcoholic cardiomyopathy. On the other hand, multiple studies have investigated low to moderate consumption of beer with interesting results. Moderate 
consumption is defined by the Dietary Guidelines for Americans as less than 1 drink per day for women or 2 drinks per day for men, one drink being equal to approximately 14 grams of pure ethanol or about $350 \mathrm{ml}$ of $5 \%$ beer.

Lipid profiles of individuals drinking traditional beer (containing alcohol) were compared to those drinking non-alcoholic beer or placebo/water. A study group of people drinking beer in a low to moderate fashion was found to have a higher total cholesterol with an increased high-density lipoprotein fraction (HDL). LDL cholesterol and triglycerides were not affected significantly by beer consumption $[6,7,10,11,12]$. Studies have also shown a decrease in overall inflammation, an effects seen in wine and beer more than in hard liquors, probably due to polyphenol content $[7,10,13,14]$.

The effects of alcohol on hypertension are not well understood, studies are contradictory, agreeing that a high level of alcohol consumption is strongly linked to the development of reversible hypertension. There seems to be no solid proof of blood pressure lowering effects of beer [7,15]. Acutely, beer does not seem to change systolic or diastolic blood pressure any more than water [8].

A twelve-week prospective study on obese individuals evaluated the effect of beer consumption on weight gain/loss and anti-oxidative properties of HDL. There was no apparent weight increase among subjects consuming moderate amounts of beer, as well as no vascular endothelial dysfunction, with a positive finding of increased anti-oxidative properties of HDL [9], which in theory could have an anti-atherogenic effect.

In conclusion, studies suggest that beer consumption can have a positive effect on serum HDL concentration with an unknown clinical relevance of that finding at this point. Other effects are also not very well defined, we do not fully understand the long term consequences of beer consumption and there is no recommendation on alcohol consumption.

\subsection{Wine}

Wine is an alcoholic beverage that has been ingrained in many cultures for hundreds of years. It is produced in many regions of the world and is a common addition to an intimate dinner or luxurious party. It is well known that irresponsible alcohol consumption is the cause of many diseases (at least 200 according to WHO) and negative health effects are observed in different age groups (including young adults in the age group 20-39 years) [24].

There are numerous studies supporting the benefits of moderate consumption of red wine, including reducing the risk of coronary heart disease (CHD) [16]. The cardioprotective ingredients contained in the wine include resveratrol. This is a polyphenolic phytoalexin analyzed for its anti-inflammatory effect. Red wine owes its beneficial impact also to the presence of anthocyanins and catechins [17]. According to research, the posistive effects of red wine consumption also affect diabetes, osteoporosis and several other diseases [18].

As is well known, excessive alcohol intake can lead to an increased risk of atrial fibrillation (AF) In addition, it is emphasized that the composition of even small doses of alcohol may be associated with some risk $[19,4]$ However, referring to recent studies, this relationship does not always apply to consumption of small and moderate amounts of wine $[21,17]$.

Why is it that wine, among other alcoholic beverages, has so many beneficial effects on the cardiovascular system? Namely, red wine contains, in addition to alcohol, numerous active compounds - polyphenols - with antioxidant and anti-inflammatory properties, which may contribute to protection against atherosclerosis [17].

There is a need to further study the effects of moderate portions of red wine on the organism, especially since the cardioprotective effect of red wine owes to several different mechanisms, not all of them have yet been thoroughly studied [22]. Consumption of red wine will not always bring beneficial health effects. According to the latest reports, doses of red 
wine have not had a positive effect on liver cell damage caused by a high-fat diet. On the contrary, the wine has increased the damage already caused [23].

Further research would ultimately help to determine the impact of optimal red wine doses on health, especially since current scientific reports of red wine consumption attribute both negative and positive health effects [23].

\subsection{High percentege alkoholic beverages}

There have been many studies that took the influence of alcoholic beverages on cardiovascular system under investigation, with most common effects on human body including hypertension (HTN), coronary heart disease (CHD), stroke, peripheral arterial disease (PAD), and cardiomyopathy [25]. However, the influence of alcohol varies with increasing amount of daily alcohol intake. It is crucial to take into consideration the percentage of alcohol consumed, as with the high-percentage alcoholic drinks the intake of "standard drinks" is exceeding the low levels with possible positive influence. A standard drink contains $0.6 \mathrm{oz}(15 \mathrm{~g})$ of ethanol. In the U.S., one drink is usually considered to be 12 $\mathrm{oz}(340 \mathrm{~g})$ of beer, $5 \mathrm{oz}(140 \mathrm{~g})$ of wine, and just 1.5 ounces $(40 \mathrm{~g})$ of spirits [26].

To properly analyze the effect of alcoholic beverages containing high amounts of ethanol on CVS, studies that differentiate between alcohol types were investigated. Consumers of fortified wine, strong beer and hard liquor had a similar, self-reported health status not only to beer and wine consumers, but most shockingly to non-consumers [27]. Adjustments for body-mass index, smoking, educational level and physical activity did not change the results, which is important to mention as usually co-factors have strong influence on the research result. However, the study results were collected during face-to-face interviews as self-reported health status, which might be the reason for not showing the significance in alcohol type in daily use.

The next study seems to bring more accurate results, as the assessment of a total of 257859 person-years follow-up on mortality was investigated. Out of total 4833 deaths within the study, 1075 were from coronary heart disease. Additional results showed, that heavy drinkers who avoided wine were at higher risk of death from all causes than were heavy drinkers who included wine in their alcohol intake. Wine drinkers had significantly lower mortality from coronary heart disease and than did non-wine drinkers [28]. This investigation shows, that not the percentage of alcohol but rather the alcohol type itself has the biggest influence on health status, and cardiovascular in particular. The positive benefits of alcohol intake were only described with wine-drinkers, whereas any other alcohol usage was not linked

to

any

health benefits.

\section{Summary}

As alcohol is a popular drink worldwide, there is a need to educate the public about the effects of alcohol consumption on health. Based on existing publications, it can be concluded that the topic of consuming small portions of red wine or beer needs to be further researched and developed in order to better understand the health effects. This is especially true given that the belief in the beneficial effects of moderate amounts of wine, for example, is widespread. When drawing conclusions about the effects of alcohol on the body, it is worth taking into account the type of alcohol, its quality and the dose consumed. It would certainly be useful to carry out studies to determine the optimum dose of red wine or beer. It is undeniable that beverages such as good quality red wine contain components which are beneficial to health, but this does not justify its excessive consumption and does not change the fact that the consumption of wine may have a negative effect on the body (which also depends to a large extent on the state of health of the patients consuming the wine)

\section{References}


1. GBD 2015 Mortality and Causes of Death Collaborators (2016). Global, regional, and national life expectancy, all-cause mortality, and cause-specific mortality for 249 causes of death, 1980-2015: a systematic analysis for the Global Burden of Disease Study 2015. Lancet (London, England), 388(10053), 1459-1544. https://doi.org/10.1016/S0140-6736(16)31012-1

2. Reamy, B. V., Williams, P. M., \& Kuckel, D. P. (2018). Prevention of Cardiovascular Disease. Primary Care: Clinics in Office Practice,45(1), 25-44. doi:10.1016/j.pop.2017.11.003

3. Mahmood, S. S., Levy, D., Vasan, R. S., \& Wang, T. J. (2014). The Framingham Heart Study and the epidemiology of cardiovascular disease: A historical perspective. The Lancet,383(9921), 999-1008. doi:10.1016/s0140-6736(13)61752-3

4. Chiva-Blanch, G., \& Badimon, L. (2019). Benefits and Risks of Moderate Alcohol Consumption on Cardiovascular Disease: Current Findings and Controversies. Nutrients, 12(1), 108. doi:10.3390/nu12010108

5. Minzer S, Losno RA, Casas R. The Effect of Alcohol on Cardiovascular Risk Factors: Is There New Information? Nutrients. 2020 Mar;12(4). DOI: 10.3390/nu12040912.

6. Spaggiari G, Cignarelli A, Sansone A, Baldi M, Santi D. To beer or not to beer: A meta-analysis of the effects of beer consumption on cardiovascular health. Plos one. 2020 ;15(6):e0233619. DOI: 10.1371/journal.pone.0233619.

7. Minzer S, Losno RA, Casas R. The Effect of Alcohol on Cardiovascular Risk Factors: Is There New Information? Nutrients. 2020 Mar;12(4). DOI: 10.3390/nu12040912.

8. Adamska, K., Krauze, T., Guzik, P., Piskorski, J., Klimas, K., \& Wykrętowicz, A. (2018). Acute cardiovascular responses elicited by consumption of beer in healthy people. Polish Archives of Internal Medicine. doi:10.20452/pamw.4266

9. Padro T, Muñoz-García N, Vilahur G, Chagas $\mathrm{P}$, Deyà A, Antonijoan RM, Badimon L. Moderate Beer Intake and Cardiovascular Health in Overweight Individuals. Nutrients. 2018 Sep 5;10(9):1237. doi: 10.3390/nu10091237. PMID: 30189619; PMCID: PMC6164820.

10. Chiva-Blanch G, Magraner E, Condines X, Valderas-Martínez P, Roth I, Arranz S, Casas R, Navarro M, Hervas A, Sisó A, Martínez-Huélamo M, Vallverdú-Queralt A, Quifer-Rada P, Lamuela-Raventos RM, Estruch R. Effects of alcohol and polyphenols from beer on atherosclerotic biomarkers in high cardiovascular risk men: a randomized feeding trial. Nutr Metab Cardiovasc Dis. 2015 Jan;25(1):36-45. doi: 10.1016/j.numecd.2014.07.008. Epub 2014 Aug 2. PMID: 25183453.

11. Huang S, Li J, Shearer GC, et al. Longitudinal study of alcohol consumption and HDL concentrations: a community-based study. The American Journal of Clinical Nutrition. 2017 Apr;105(4):905-912. DOI: 10.3945/ajen.116.144832

12. Gaetano, G. D., Costanzo, S., Castelnuovo, A. D., Badimon, L., Bejko, D., Alkerwi, A., . . . Iacoviello, L. (2016). Effects of moderate beer consumption on health and disease: A consensus document. Nutrition, Metabolism and Cardiovascular Diseases, 26(6), 443-467. doi:10.1016/j.numecd.2016.03.007

13. Pounis G, Bonaccio M, Di Castelnuovo A, Costanzo S, de Curtis A, Persichillo M, Sieri S, Donati MB, Cerletti C, de Gaetano G, Iacoviello L. Polyphenol intake is associated with low-grade inflammation, using a novel data analysis from the Molisani study. Thromb Haemost. 2016 Jan;115(2):344-52. doi: 10.1160/TH15-06-0487. Epub 2015 Sep 10. PMID: 26355794.

14. González R, Ballester I, López-Posadas R, Suárez MD, Zarzuelo A, MartínezAugustin O, Sánchez de Medina F. Effects of flavonoids and other polyphenols on 
inflammation. Crit Rev Food Sci Nutr. 2011 Apr;51(4):331-62. doi: 10.1080/10408390903584094. PMID: 21432698.

15. Puddey IB, Mori TA, Barden AE, Beilin LJ. Alcohol and Hypertension-New Insights and Lingering Controversies. Curr Hypertens Rep. 2019 Sep 7;21(10):79. doi: 10.1007/s11906-019-0984-1. PMID: 31494743.

16. L. Castaldo et al., "molecules Red Wine Consumption and Cardiovascular Health," doi: 10.3390/molecules24193626.

17. C. L et al., "Red Wine Consumption and Cardiovascular Health," Molecules, vol. 24, no. 19, Oct. 2019, doi: 10.3390/MOLECULES24193626.

18. D.-V. P et al., "The Fluid Aspect of the Mediterranean Diet in the Prevention and Management of Cardiovascular Disease and Diabetes: The Role of Polyphenol Content in Moderate Consumption of Wine and Olive Oil," Nutrients, vol. 11, no. 11, Nov. 2019, doi: 10.3390/NU11112833.

19. A. S, C.-B. G, V.-M. P, M.-R. A, L.-R. RM, and E. R, "Wine, beer, alcohol and polyphenols on cardiovascular disease and cancer," Nutrients, vol. 4, no. 7, pp. 759781, 2012, doi: 10.3390/NU4070759.

20. C.-B. G and B. L, "Benefits and Risks of Moderate Alcohol Consumption on Cardiovascular Disease: Current Findings and Controversies," Nutrients, vol. 12, no. 1, Jan. 2019, doi: 10.3390/NU12010108.

21. S. LS, A. ED, M. MM, G. J, and M. A, "Red Wine, Resveratrol and Atrial Fibrillation," Nutrients, vol. 9, no. 11, Nov. 2017, doi: 10.3390/NU9111190.

22. P. XL et al., "Resveratrol ameliorates high glucose and high-fat/sucrose diet-induced vascular hyperpermeability involving Cav-1/eNOS regulation," PLoS One, vol. 9, no. 11, Nov. 2014, doi: 10.1371/JOURNAL.PONE.0113716.

23. B. TP et al., "Effects of grape juice, red wine and resveratrol on liver parameters of rat submitted high-fat diet," An. Acad. Bras. Cienc., vol. 92, no. 2, pp. 1-18, 2020, doi: 10.1590/0001-3765202020191230.

24. https://www.who.int/news-room/fact-sheets/detail/alcohol access 22.09

25. Piano M. R. (2017). Alcohol's Effects on the Cardiovascular System. Alcohol research : current reviews, 38(2), 219-241.

26. Lucas, D. L., Brown, R. A., Wassef, M., \& Giles, T. D. (2005). Alcohol and the Cardiovascular System. Journal of the American College of Cardiology,45(12), 19161924. doi:10.1016/j.jacc.2005.02.075

27. Theobald, H. (2003). Influence Of Different Types Of Alcoholic Beverages On SelfReported Health Status. Alcohol and Alcoholism,38(6), 583-588. doi:10.1093/alcalc/agg 115

28. Grønbaek, M. N., Sørensen, T. I., Johansen, D., Becker, U., Gottschau, A., Schnohr, P., Hein, H. O., \& Jensen, G. (2001). Øl, vin, spiritus og dØdelighed [Beer, wine, spirits and mortality]. Lakartidningen, 98(21), 2585-2588. 